\title{
The Rights of Persons with Disabilities
}

The UN International Convention on the Rights of Persons with Disabilities (CRPD) defines a disability as a long-term physical, mental, intellectual or sensory impairment which may hinder a person's full and effective participation in society on an equal basis with others. ${ }^{3}$ The principle of equality is contained within this definition, seeking to ensure this for persons with a disability of any kind.

According to current estimates, 650 million people live with a disability, making them the world's largest minority. In many parts of the world persons with disabilities are subject to severe social stigma. This has created a culture of marginalisation and routine discrimination, forcing people to live under the misguided belief that their lives are shameful and not worthy of respect.

Many people with disabilities are subject to aggravated forms of discrimination based on their gender, race, ethnicity, social status or age as well as their disability. Women and girls with disabilities are often subject to higher rates of violence, neglect and exploitation than those without. Most children with disabilities in developing countries do not attend school. There is also an unarguable connection between poverty and disability, with an estimated 20 per cent of the world's poorest people living with a disability.

3 UN document. Please see: http://www.ohchr.org/EN/HRBodies/CRPD/Pages/Convention.aspx 
When the CRPD came into force in 2008 it set an international standard that recognises the equal worth and dignity of all persons living with a disability. The convention emphasises the right of all persons to live autonomously and to live in a society which actively encourages their participation in all spheres of life. Most importantly, the convention recognises that persons with disabilities should enjoy these rights on an equal footing with others. This requires states to take action to ensure that these obligations are met. It means ensuring equal opportunities in education and in the work place. It means publishing information in accessible formats such as Braille, audio or large print and allocating funding to develop inclusive cultural and leisure activities. Most importantly, it means changing the way that persons with disabilities are perceived and treated in society.

As of 201095 states are party to CRPD, and 22 per cent (23 countries) of these states are members of the Commonwealth. The effort to ensure that persons with disabilities enjoy the same rights as others has begun, but the challenge remains to fulfil the promise. 